\title{
De invloed van de schoolcontext op de effecten van de Gezonde Basisschool van de Toekomst
}

\author{
Nina Bartelink - Patricia van Assema - Stef Kremers · Hans Savelberg • Maria Jansen
}

(C) The Author(s) 2020

\begin{abstract}
Samenvatting
Inleiding Scholen zijn een belangrijke setting om gezondheidsgedrag van kinderen te verbeteren. Het initiatief 'De Gezonde Basisschool van de Toekomst (GBT)' heeft als doel om gezondheid en welzijn te integreren in het schoolsysteem en is gebaseerd op de door de Wereldgezondheidsorganisatie ontwikkelde Health Promoting School (HPS)-benadering. Uitgangspunten voor GBT zijn het aanbieden van een gezonde lunch en een gestructureerd beweegen cultuuraanbod met verruiming van schooltijd. In dit artikel worden de effecten na twee jaar followup en de invloed van de context op deze effecten beschreven.

Methode GBT is geïmplementeerd in vier basisscholen in de Parkstadregio (Zuid-Limburg) en vergeleken met vier controlescholen. De gegevens zijn verzameld via onder andere antropometriemetingen, vragenlijsten, interviews en observaties.

Resultaten GBT heeft geleid tot verbeteringen in het voedings- en beweeggedrag van kinderen en tot een gezondere gewichtsstatus van deze kinderen. De
\end{abstract}

N. Bartelink $(\bowtie) \cdot$ P. van Assema $\cdot$ M. Jansen

Department of Health Promotion, Care and Public Health Research Institute (CAPHRI), Maastricht University,

Maastricht, Nederland

n.bartelink@maastrichtuniversity.nl

M. Jansen

Maria.jansen@ggdzl.nl

N. Bartelink · P. van Assema · S. Kremers · H. Savelberg Department of Health Promotion, School of Nutrition and Translational Research in Metabolism (NUTRIM), Maastricht University, Maastricht, Nederland

\section{Jansen}

Academische Werkplaats Publieke Gezondheid Limburg, GGD Zuid Limburg, Heerlen, Nederland schoolcontext bleek op diverse manieren van invloed te zijn op de gevonden effecten.

Conclusie GBT is een haalbare uitwerking van de HPSbenadering gebleken. Het is een veelbelovend initiatief dat passend en effectief is om de gezondheid en het gezondheidsgedrag van kinderen te verbeteren. Wanneer scholen als complex en adaptief worden beschouwd, kan dat bijdragen aan een betere integratie en evaluatie van gezondheidsbevordering op scholen.

Trefwoorden basisschool context . gezondheidsbevordering $\cdot$ voeding $\cdot$ beweging

The influence of the school context on the effects of the Healthy Primary School of the Future
Abstract
Introduction Schools play an important role in pro- moting healthy behaviours in children. The initiative 'The Healthy Primary School of the Future (HPSF)' aims to integrate health and wellbeing into the school system and is based on the principles of the Health Promoting School approach (HPS), developed by WHO. HPSF is characterized by a free healthy lunch each day and daily structured physical activity and cultural sessions. This paper describes the effects of HPSF after two-year follow-up and the influence of the school context on these effects.
Method HPSF has been implemented in four primary schools in the Parkstad region (southern part of Lim- burg) and has been compared to four control schools. Data collection consisted of among others anthropo- metric measurements, questionnaires, interviews and observations.
Results HPSF has led to improved dietary and PA be- haviours of children and a healthier weight status in 
these children. The school context influenced these effects in several different ways.

Conclusion HPSF can be considered as a feasible translation of the HPS-approach. It is a promising initiative that is suitable and effective to improve children's health and health behaviours. Embracing the complex and adaptive nature of schools can contribute to a better integration and evaluation of health promotion in schools.

Keywords Primary school · Context · Health promotion $\cdot$ Nutrition $\cdot$ Physical activity

\section{Inleiding}

Scholen worden gezien als een belangrijke setting om de gezondheid en het gezondheidsgedrag van kinderen te verbeteren [1]. De Wereldgezondheidsorganisatie (WHO) heeft de Health Promoting School (HPS)benadering ontwikkeld, met als doel gezondheid en welzijn te integreren in het schoolsysteem [2]. Onderliggende principes hierbij zijn een whole-school approach, waarbij de focus niet alleen ligt op educatie, maar ook op de schoolomgeving, het schoolbeleid en het curriculum. Daarnaast zijn actieve betrokkenheid van de medewerkers op school en continue monitoring, bijstelling en evaluatie van belang. Deze principes worden wereldwijd geaccepteerd, maar de concrete toepassing kan per regio of land verschillen $[3,4]$. In Europa zijn deze principes door het Schools for Health in Europe-netwerk (SHE) omgezet in zes basiscomponenten, namelijk 1) schoolgezondheidsbeleid, 2) de fysieke schoolomgeving, 3) de sociale schoolomgeving, 4) gezondheidsvaardigheden en -competenties, 5) samenwerking met de wijk en 6) gezondheidsvoorzieningen [5]. In Nederland heeft het geleid tot het nationale Programma Gezonde School [6]. Ook binnen zo'n Europees netwerk of nationaal programma kan de HPS-benadering op allerlei manieren vertaald worden naar de daadwerkelijke praktijk op een school, zodat ze past binnen de specifieke context van die school. Binnen het SHE-netwerk wordt dit ook wel navigeren genoemd [7].

Een mogelijke praktische uitwerking van de principes van de HPS-benadering is de Gezonde Basisschool van de Toekomst (GBT). Dit initiatief is ontwikkeld door de Onderwijsstichting Movare, de GGD Zuid Limburg en de Maastricht University. De aanleiding voor dit initiatief was de hardnekkige gezondheidsachterstand in Zuid-Limburg, die van generatie op generatie wordt overgedragen. Leerkrachten in het primair onderwijs zagen een verslechtering van de gezondheid van hun leerlingen, resulterend in een niet optimale talentontwikkeling, tegenvallende leerprestaties en hoger schoolverzuim dan gemiddeld in Nederland [8]. Vanuit deze constatering stelde Onderwijsstichting Movare haar onderwijsfilosofie bij, in die zin dat ze niet de opvoedingstaken van de ouders wil overnemen, maar als school het goede voorbeeld wil- len geven wat betreft voeding en bewegen, zij aan zij met de ouders. Zo is gedurende twee jaar (2013-2015) met leerkrachten, ouders en externe partners de GBT ontwikkeld. Top-down waren de uitgangspunten: een gezonde schoollunch en professioneel begeleide beweeg- en cultuuractiviteiten tijdens de tussenschoolse opvang.

Movare gaf bij aanvang al aan dat het nieuwe concept bij gebleken succes breed zou worden doorgevoerd en dat de concrete uitwerking moest aansluiten bij de schoolcontext. Elke school is uniek en vraagt een passende uitwerking, die bij succes structureel wordt doorgevoerd en de nieuwe routine van de school wordt. Daarom worden de scholen bij de uitwerking van het GBT-concept als complex en adaptief beschouwd. Met andere woorden, scholen zijn dynamisch, passen zich aan veranderende omstandigheden aan en bestaan uit een schoolcontext met componenten die met elkaar in interactie zijn, bijvoorbeeld tussen de mensen in de school, maar ook tussen de fysieke, culturele, beleidsmatige en sociale elementen van een school, en tussen de school en de wijk $[4,9,10]$. Een schoolcontext kan gezien worden als de specifieke omstandigheden en karakteristieken van de school, zoals de sociale, politieke, economische en fysieke omgeving, de eigenschappen, gedragingen, wensen en benodigdheden van de mensen in de school, de bredere schoolomgeving, en het verleden en de organisatie van de school [11, 12]. Iedere school heeft dus zijn eigen context en daarom is het belangrijk dat iedere school zelf moet kunnen beslissen óf en hoe deze bepaalde veranderingen wil doorvoeren. Dit betekent dat het GBT-concept om flexibiliteit vraagt, zodat scholen GBT kunnen aanpassen aan veranderende omstandigheden. Door cocreatie tot stand te brengen tussen scholen, ouders en externe partners is GBT concreet uitgewerkt op een manier die past binnen de specifieke schoolcontext.

Wanneer scholen als complex en adaptief worden beschouwd, heeft dat consequenties voor de implementatie, bijstelling en evaluatie van het GBT-concept. Om deze reden is er een programmatheorie ontwikkeld [13] en is voor de evaluatie een contextueel actiegerichte onderzoeksbenadering uitgewerkt (Engelstalige afkorting: CARA) [14]. Het doel van deze aanpak is om zowel de GBT zo goed mogelijk te evalueren, als de scholen te begeleiden en ondersteunen bij het veranderingsproces, met een specifieke focus op de schoolcontext. Meer informatie over deze onderzoeksbenadering is elders beschreven [14].

Relevant was om niet alleen te onderzoeken óf de GBT werkt, maar ook hoe, waar, voor wie en onder welke omstandigheden. Dit artikel beschrijft de effecten en de invloed van de schoolcontext op deze effecten. De effecten van de GBT betreffen de BMI $\mathrm{z}$-score van kinderen en hun voedings- en beweeggedrag na twee jaar blootstelling, en waar, voor wie en onder welke omstandigheden deze effecten gevonden zijn. Het GBT-onderzoek omvatte naast deze effect- 
Tabel 1 De volledige en gedeeltelijke GBT $[13,19]$

\begin{tabular}{|c|c|c|}
\hline & Volledige GBT & Gedeeltelijke GBT \\
\hline Schooltijden & $\begin{array}{l}\text { Verlengde schooldag ( } 90 \text { minuten totaal), school uit rond 15:30, } \\
\text { 15:45 uur }\end{array}$ & Geen verlengde schooldag, school uit rond 15:00 uur \\
\hline Voeding & $\begin{array}{l}\text { Leerlingen krijgen iedere dag een gratis gezond tussendoortje en } \\
\text { gezonde lunch ( } 30 \text { minuten) op school }\end{array}$ & Leerlingen eten eigen lunch thuis of op school (15 minuten) \\
\hline Beweging & $\begin{array}{l}\text { Dagelijks gestructureerd beweeg- en cultuuraanbod (ongeveer } \\
60 \text { minuten) na de lunch }\end{array}$ & $\begin{array}{l}\text { Dagelijks gestructureerd beweeg- en cultuuraanbod (onge- } \\
\text { veer } 60 \text { minuten) na de lunch }\end{array}$ \\
\hline Pedagogisch medewerkers & Begeleiden lunch en beweeg- en cultuuraanbod na de lunch & Begeleiden alleen beweeg- en cultuuraanbod na de lunch \\
\hline $\begin{array}{l}\text { Andere gezondheidsbevorde- } \\
\text { rende aanpassingen }\end{array}$ & $\begin{array}{l}\text { Toegang tot de 'fruitmand', onder andere traktatiebeleid aange- } \\
\text { past en drinken van water gestimuleerd }\end{array}$ & $\begin{array}{l}\text { Toegang tot de 'fruitmand', weinig tot geen extra aanpas- } \\
\text { singen }\end{array}$ \\
\hline Organisatie op school & $\begin{array}{l}\text { Een al op de school werkzame leraar of interne begeleider is als } \\
\text { schoolcoördinator aangesteld }\end{array}$ & $\begin{array}{l}\text { Een al op de school werkzame leraar of intern begeleider is } \\
\text { als schoolcoördinator aangesteld }\end{array}$ \\
\hline Bottom-up betrokkenheid & $\begin{array}{l}\text { Leerlingenraad en werkgroepen en klankbordgroepen met lera- } \\
\text { ren en ouders opgezet }\end{array}$ & $\begin{array}{l}\text { Leerlingenraad en werkgroepen en klankbordgroepen met } \\
\text { leraren en ouders opgezet }\end{array}$ \\
\hline
\end{tabular}

evaluatie ook een procesevaluatie [13, 15-18]. Waar dat zinvol is, verwijzen we naar de verschillende eerder verschenen wetenschappelijke publicaties.

\section{Methode}

\section{Het proces rond de Gezonde Basisschool van de Toekomst}

Elf van de 56 Movare-scholen zijn benaderd voor deelname als interventieschool, waarvan vier scholen serieus interesse bleken te hebben. Met hen is een intensief voorbereidingstraject (schooljaar 2014-2015) doorlopen om voldoende draagvlak te creëren onder alle betrokkenen en om samen met hen het GBT-concept vorm te geven op een manier die binnen de school past. Deze vorm van cocreatie hield niet op na het voorbereidingsjaar, maar werd gedurende de uitvoering van de GBT voortgezet. Welke veranderingen precies zijn doorgevoerd en op welke manier dat is gedaan is volledig de keuze geweest van de betrokkenen op school. Uiteindelijk zijn er twee varianten van de GBT ontstaan (tab. 1; [13, 19]). Twee van de vier deelnemende scholen hebben dagelijks een gezond tussendoortje, een gezonde lunch (30 minuten) en een gestructureerd beweeg- en cultuuraanbod (ongeveer 60 minuten) gedurende een verlengde schooldag (90 minuten totaal), hier verder beschreven als de volledige Gezonde Basisscholen van de Toekomst (volledige GBT). Zowel de lunch als het gestructureerde aanbod is gratis en wordt begeleid door pedagogisch medewerkers van kinderopvangorganisaties. De andere twee deelnemende scholen hebben alleen het beweeg- en cultuuraanbod ingevoerd (geen lunch en geen verlengde schooldag), hier verder beschreven als de gedeeltelijke Gezonde Basisscholen van de Toekomst (gedeeltelijke GBT).

Naast de twee grote veranderingen hebben de scholen ook naar keuze andere gezondheidsbevorderende aanpassingen doorgevoerd. Om scholen te ondersteunen bij hun keuze is de zogenaamde 'fruitmand' ontwikkeld [14], opgesteld door de onderzoekers van Maastricht University en gebaseerd op evi- dence-based gezondheidsbevorderende interventies uit de RIVM-database en practice-based interventies. Vooral op de volledige GBT-scholen zijn extra gezondheidsbevorderende veranderingen uit de 'fruitmand' overgenomen, zoals een gezond traktatiebeleid en het stimuleren van het drinken van water op school [13].

Om alle veranderingen op de vier scholen tot stand te brengen is op elke school een leraar of interne begeleider als schoolcoördinator aangesteld. Er is tevens een samenwerkingsverband gecreëerd met expertise en inbreng van de vele verschillende betrokken partners, onder wie schoolcoördinatoren, Movare, Maastricht University, GGD Zuid Limburg, kinderopvangorganisaties, een cateringbedrijf, combinatiefunctionarissen voor beweging en cultuur, en de Provincie Limburg, die het initiatief heeft gefinancierd. Het samenwerkingsproces bestond uit een samenspel van top-down aangeleverde kennis, zoals de 'fruitmand', en bottom-up aangereikte ideeën door alle bij GBT betrokken partners [13].

\section{De gezondheid en het gezondheidsgedrag van kinderen}

De effecten van twee jaar GBT zijn onderzocht op vele verschillende uitkomstmaten, waarbij de focus in dit artikel ligt op de BMI z-score van de kinderen, de primaire uitkomstmaat, en hun voedings- en beweeggedrag, de secundaire uitkomstmaten [15, 16]. Voor het complete onderzoek is gebruikgemaakt van een quasi-experimenteel onderzoeksontwerp. Ethische goedkeuring is verkregen vanuit de METC Zuyderland in Heerlen (MEC 14-N-142).

Naast de vier deelnemende scholen zijn ook vier controlescholen van dezelfde onderwijsstichting geïncludeerd, alle op basis van vrijwillige deelname. Metingen zijn jaarlijks uitgevoerd in de periode september tot en met november: de nulmeting (T0) in 2015, en eerste en tweede follow-up in 2016 (T1) en 2017 (T2). Bij iedere meetronde was het onderzoeksteam voor alle metingen een week lang op een school aanwezig. Alle kinderen (vanaf groep 2) op de acht deelnemende scholen ( $n=2.326$ op T0) en hun ouders zijn 
Tabel 2 Het meten van de verschillende aspecten van de context [13]

\begin{tabular}{l|l}
\hline $\begin{array}{l}\text { Aspecten van de context } \\
\text { Leraarspraktijken op het gebied van voeding en beweging, zoals regels, voorbeeldgedrag, aanmoedi- }\end{array}$ & $\begin{array}{l}\text { Meetmethode } \\
\text { Praktijkenvragenlijst voor leraren }\end{array}$ \\
\hline $\begin{array}{l}\text { Eigenschappen van de schoolpopulatie, zoals geslacht, etniciteit, BMI z-score bij de start } \\
\text { Stimulerende elementen in de schoolomgeving voor gezonde voeding en beweging, zoals beweegvrien- } \\
\text { delijk schoolplein, gezond traktatiebeleid }\end{array}$ & $\begin{array}{l}\text { Semigestructureerde interviews, observaties, syste- } \\
\text { metingen }\end{array}$ \\
\hline $\begin{array}{l}\text { Ervaren barrières van schoolmedewerkers bij het uitvoeren van gezondheidsbevorderende activiteiten, } \\
\text { zoals onvoldoende tijd, te ingewikkeld, weinig steun }\end{array}$ & $\begin{array}{l}\text { Barrièrevragenlijst voor leraren en pedagogisch } \\
\text { medewerkers }\end{array}$ \\
\hline Grote organisatorische kwesties op school, zoals een fusieproces & $\begin{array}{l}\text { Semigestructureerde interviews, observaties, syste- } \\
\text { matische aantekeningen }\end{array}$ \\
\hline
\end{tabular}

uitgenodigd voor deelname aan het onderzoek. Alleen wanneer een toestemmingsformulier was ingevuld en ondertekend door (een van) de ouder(s), was deelname aan het onderzoek mogelijk. In de metingen zijn onder andere opgenomen: lengte, gewicht, ouder- en kindvragenlijsten met vragen gebaseerd op de landelijke Gezondheidsmonitors en een beweegmeter (Actigraph GT3X+, 30 Hz, 10s epoch), die gedurende een week gedragen werd. De BMI z-score is verkregen door de BMI te bepalen aan de hand van het gewicht en de lengte van het kind. Vervolgens is deze op basis van Nederlandse referentiewaarden gestandaardiseerd door een correctie voor leeftijd en geslacht [20]. Informatie over het sedentaire gedrag, lichte fysieke activiteit en matig tot intensieve fysieke activiteit zijn verkregen via de beweegmetergegevens aan de hand van Evensons afkapwaarden [21]. Gegevens over het voedingsgedrag van kinderen zijn afkomstig uit de vragenlijstgegevens (de totaalscores voor gezond en ongezond voedingsgedrag uit de oudervragenlijst, de rest uit de kindvragenlijsten). De effecten van de GBT zijn onderzocht door middel van statistische toetsing, waarbij gebruik is gemaakt van linear mixed models via SPSS. Bij iedere analyse is gecorrigeerd voor geslacht, leerjaar bij de start, etniciteit, sociaaleconomische achtergrond en BMI z-score bij de start (alleen voor de gedragsuitkomstmaten). Meer informatie over de gegevensverzameling, -verwerking en -analyse is te vinden in eerder gepubliceerde artikelen [15, 16].

\section{De schoolcontext}

Om de schoolcontexten te karakteriseren zijn de aspecten geselecteerd waarvan uit de wetenschappelijke literatuur bekend is dat ze van invloed zijn op gezondheidsbevordering op school. Dit zijn de praktijken van leraren op het gebied van voeding en beweging [22], eigenschappen van de schoolpopulatie [23], stimulerende elementen in de schoolomgeving voor gezonde voeding en beweging [24], ervaren barrières van schoolmedewerkers bij het uitvoeren van gezondheidsbevorderende activiteiten [25] en grote organisatorische issues op school [23]. De gegevens zijn verzameld van 2015 tot 2017 [13, 17, 18], waarbij zowel kwalitatieve als kwantitatieve onderzoeksmethoden zijn gebruikt. Semigestructureerde interviews zijn jaarlijks gehouden met projectleiders en schoolcoördinatoren, de vragenlijsten zijn twee keer per jaar afgenomen bij leraren en pedagogisch medewerkers, een van de onderzoekers heeft op regelmatige basis observaties uitgevoerd en systematische aantekeningen in een dagboek bijgehouden, en notulen van diverse school- en projectoverleggen zijn geanalyseerd. De verschillende aspecten van de schoolcontext en hoe deze gemeten zijn, zijn weergegeven in tab. 2. Om te onderzoeken welke invloed de schoolcontext op de effecten heeft, zijn de context- en effectgegevens samengebracht. Op het niveau van het kind is dit gedaan door de effectgegevens uit te splitsen naar twee specifieke settings (op school en thuis) en door gebruik te maken van subgroepanalyses op basis van geslacht, leerjaar, gewichtsstatus en sociaaleconomische achtergrond. Op het niveau van de school is dit gedaan door een kwalitatieve vergelijking te maken tussen de scholen die qua uitwerking van de GBT het meest op elkaar leken. Dit betekent dat de twee volledige GBT met elkaar zijn vergeleken, en ook de twee gedeeltelijke GBT. Meer informatie over de gegevensverzameling, -verwerking en -analyse is beschreven in eerder gepubliceerde artikelen [13, 17, 18].

\section{Resultaten}

Op baseline heeft $60,3 \%$ van de kinderen meegedaan $(n=1.403)$. Door het dynamische cohort hebben na twee jaar follow-upperiode in totaal 1974 kinderen en hun ouders met minimaal één meting deelgenomen aan het onderzoek. Van hen zijn 1.676 kinderen geïncludeerd in de analyses. Hiervoor hanteerden we de volgende inclusiecriteria: een kind zat al op school op baseline (maximaal groep 7) en is tijdens de twee jaar follow-upperiode niet van school veranderd. Representativiteitsanalyses toonden aan dat er amper sprake is van selectieve deelname aan het onderzoek. De onderzoekspopulatie was vergelijkbaar met andere schoolkinderen in de regio, maar er waren wel duidelijke verschillen in sociaaleconomische achtergrond, etniciteit en beweeggedrag ten opzichte van het gemiddelde in Nederland [26]. 
Figuur 1 Effect van de GBT op het voedings- en beweeggedrag van kinderen na twee jaar follow-up in vergelijking met de controlescholen, weergegeven in effectgroottes [15]. * Significant $(p<0,05)$ verschil tussen de volledige GBT- en de controlescholen. ${ }^{* *}$ Significant $(p<0,05)$ verschil tussen de gedeeltelijke GBTen de controlescholen

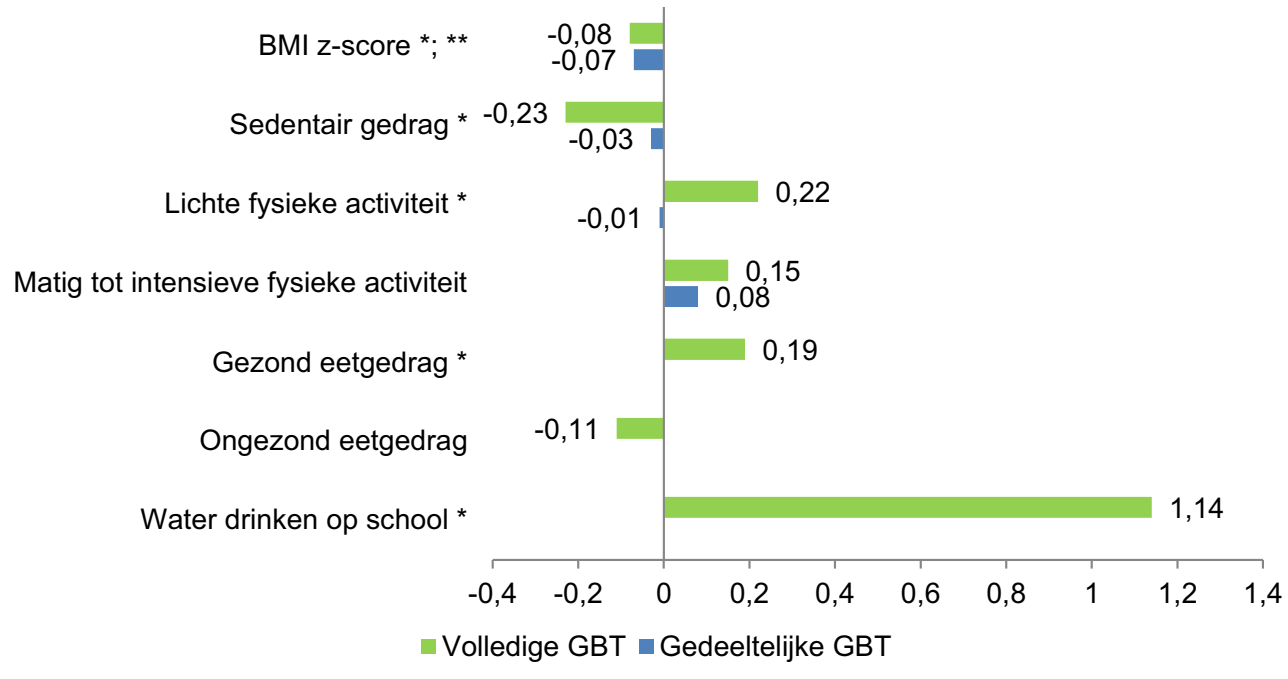

Fruit tijdens lunch

Figuur 2 Effect van de GBT op de lunchinname van kinderen na twee jaar follow-up in vergelijking met de controlescholen, weergegeven in oddsratio's [15]. * Significant $(p<0,05)$ verschil tussen de volledige GBT en de controlescholen

Groente tijdens lunch *

Granen tijdens lunch *

Zuivel tijdens lunch *

Water tijdens lunch

Boter tijdens lunch *

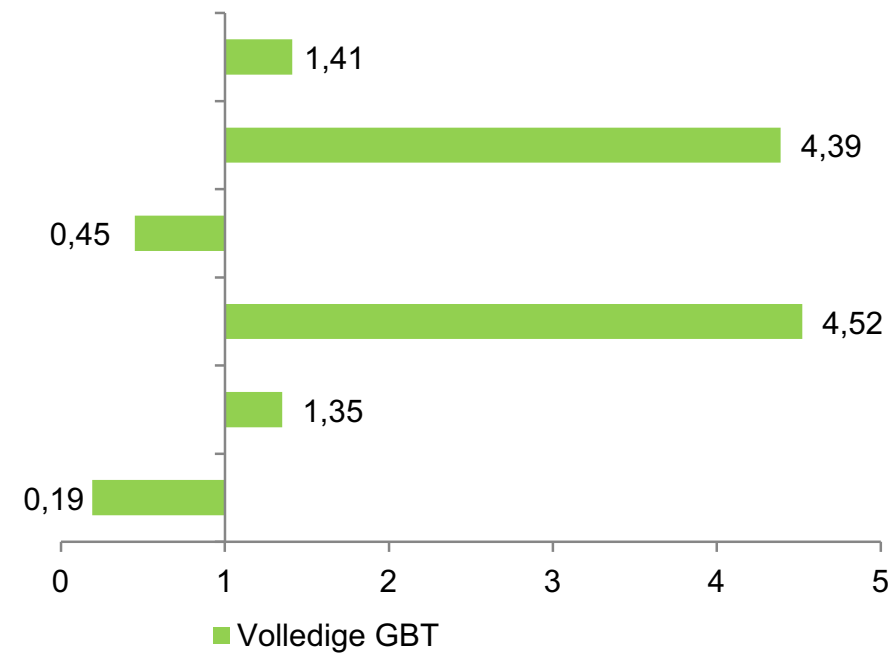

De effecten van de GBT op de gezondheid en het gezondheidsgedrag van de kinderen

De BMI z-score van de kinderen op de vier GBT-scholen is na twee jaar significant afgenomen in vergelijking met die van de kinderen op de controlescholen (fig. 1). Op deze controlescholen is de BMI z-score van kinderen na twee jaar toegenomen [16]. Op de volledige GBT-scholen is het voedings- en beweeggedrag significant verbeterd (fig. 1 en 2; [15]). Deze kinderen eten vaker groente en zuivel tijdens de lunch en de inname van granen en boter is tijdens de lunch afgenomen. Daarnaast zijn deze kinderen op school meer water gaan drinken. Ten slotte is het beweeggedrag van de kinderen op de volledige GBT-scholen significant veranderd: kinderen zitten minder en hun lichte, fysieke activiteit, zoals wandelen, is toegenomen. Het beweeggedrag van kinderen op de gedeeltelijke GBTscholen is daarentegen niet significant veranderd [15].
De schoolcontext op kindniveau: waar en voor wie is de GBT het meest effectief?

Bij het uitsplitsen van het voedings- en beweeggedrag naar de schoolsetting en de thuissetting, blijkt dat op de volledige GBT-school het voedings- en beweeggedrag is verbeterd [18]. Deze kinderen compenseren hun voedingsgedrag thuis niet en ze zijn ook thuis meer gaan bewegen. Op de gedeeltelijke GBT is het beweeggedrag op school verbeterd, maar is er thuis voor gecompenseerd, waardoor het opgeteld niet significant is verbeterd. Verder zijn bij beide varianten van de GBT de effecten op het beweeggedrag op school gunstiger voor de oudere kinderen (groep 5-8 versus groep 1-4). Ook zijn de effecten thuis gunstiger voor kinderen met een hogere sociaaleconomische achtergrond. In het algemeen gelden de positieve effecten op de volledige GBT-scholen voor kinderen uit gezinnen met een hoge en kinderen uit gezinnen met een lage sociaaleconomische achtergrond. Dit geldt minder sterk voor de gedeeltelijke GBT-scholen, waar vooral de kinderen uit de hoge sociaaleconomische klasse meer profiteren [18]. 
De schoolcontext op schoolniveau: onder welke omstandigheden is de GBT het meest effectief?

De vergelijking tussen de twee volledige GBT-scholen en die tussen de twee gedeeltelijke GBT-scholen laten enkele duidelijke overeenkomsten in de context van de school zien die invloed lijken te hebben op de effecten [17]. Kijkend naar het gemiddelde van de kinderen op de scholen lijken de sociaaleconomische achtergrond van kinderen en hun gezondheidsgedrag bij de start van GBT van invloed te zijn. Scholen met gemiddeld veel kinderen uit gezinnen met een lage sociaaleconomische klasse bereiken minder gunstige effecten. Daarnaast zijn er ook minder gunstige effecten gevonden voor scholen met gemiddeld veel kinderen met een slechtere startpositie op baseline (T0). Gekeken naar het gemiddelde van de medewerkers lijken de voedings- en beweegpraktijken van leraren op school en in de klas van invloed te zijn, net als de ervaren barrières van de externe pedagogische medewerkers. De gunstigste effecten zijn gevonden op scholen waar de voedings- en beweegpraktijken van leraren gemiddeld het meest verbeterden en waar de externe pedagogisch medewerkers gemiddeld de minste barrières ervaarden. Gekeken naar de schoolorganisatie lijkt van invloed te zijn in hoeverre een school de veranderingen behorende bij de GBT op een positieve manier wist samen te brengen met een eventuele andere grote organisatorische verandering. Gunstigere effecten zijn bijvoorbeeld gevonden voor de school die een geheel nieuwe start maakte door de invoering van de GBT samen te brengen met de start als fusieschool en de intrede in een nieuw schoolgebouw [17].

\section{Beschouwing}

Dit onderzoek beschrijft de effecten van de GBT en de invloed van de schoolcontext op deze effecten. Het toepassen van een contextueel actiegerichte onderzoeksbenadering heeft hierbij geholpen om meer inzicht te krijgen in iedere schoolcontext en de continue interactie ervan met de GBT-uitvoering [12].

De resultaten van het onderzoek gericht op de effecten van de GBT laten verbeteringen zien in de BMI $\mathrm{z}$-score van kinderen en hun voedings- en beweeggedrag. De gevonden resultaten laten daarbij duidelijk zien dat de volledige GBT in vergelijking met de gedeeltelijke GBT effectiever is in het verbeteren van de gezondheid en het gezondheidsgedrag van de kinderen, ongeacht de sociaaleconomische status meer gelijke effecten oplevert voor alle kinderen en met meer succes een transitie naar de thuissituatie bewerkstelligt. De impact van de volledige GBT lijkt dus groter in het bewerkstelligen van effecten op BMI en gedrag over de SES-gradiënt heen, wat mogelijk verklaard kan worden door het disruptieve effect van de lunch en de ontstane synergie door de focus op zowel voedingsals bewegingsgedragingen [27, 28]. Het verstrekken van een schoollunch kan beschouwd worden als een grote ontregeling, ofwel een disruptie in het licht van de Nederlandse basisschooltraditie. In beide varianten van de GBT zijn echter significante effecten gevonden op de BMI z-score van kinderen, wat heeft geresulteerd in een gezondere gewichtsstatus. Deze effecten zijn veelbelovend, ook al geven ze volgens de richtlijnen van Lipsey een klein effect weer [29]. Daarvoor zijn drie redenen: 1) ze zijn al na twee jaar van implementatie zichtbaar, 2) ze tonen een verandering aan in de bestaande BMI-trend, die zichtbaar werd op de controlescholen, en 3$)$ de effectgroottes $(0,07$ en 0,08 ) liggen iets hoger dan de effectgroottes die resulteren uit meta-analyses van andere schoolinterventies [30-32].

De resultaten van het onderzoek laten vervolgens ook duidelijk zien dat de schoolcontext niet alleen van invloed is op het proces van uitvoering van de GBT, maar ook op de effecten van de GBT. Deze interactie met de schoolcontext geeft aan dat het integreren van gezondheidsbevordering in een schoolsysteem geen lineair traject is met een begin en een einde, maar een non-lineair, complex en dynamisch proces [9, 33], waarbij de effecten niet gelijk hoeven te zijn voor ieder kind en iedere school. Scholen zijn open organisaties, waardoor (gedrags)veranderingen in de school altijd in interactie staan met de andere leefwerelden van het kind, zoals de thuisomgeving en de wijk [34]. De resultaten van het onderzoek laten deze interactie ook zien, waarbij minder gunstige effecten zijn gevonden in de thuissituatie voor kinderen met een lagere sociaaleconomische achtergrond. Voor duurzame effecten is het van belang om een gezonde thuisomgeving én een gezonde school aan te moedigen, zodat er consistentie komt tussen de verschillende leefwerelden van het kind en daar dezelfde sociale norm wordt uitgedragen [35]. In toekomstig onderzoek dient nadrukkelijk rekening te worden gehouden met de sociaaleconomische status, waarbij in cocreatie met de lage statusgroep gezocht wordt naar effectversterkingsmechanismen. Scholen met gemiddeld veel kinderen uit lage sociaaleconomische statusgroepen en met een slechtere startpositie wat betreft gewicht en gedrag moeten beseffen dat zij een extra maatschappelijke opgave aangaan.

De interactie met de schoolcontext betekent ook dat het niet werkt om scholen top-down een standaardprogrammapakket aan te bieden [12]. Door het initiëren van een cocreatieproces zijn top-downen bottom-upkennis gecombineerd en kon rekening worden gehouden met de specifieke schoolcontext [36]. Door zo'n intensief cocreatieproces kon verandering tot stand komen, waarbij de school inspraak en medezeggenschap ervaart [13]. Een continu proces van trial en error, feedback loops en inbreng van alle betrokkenen is hierbij van groot belang. Dus niet alleen de bottom-upinbreng van betrokkenen op school, zoals medewerkers, maar ook die van ouders en kinderen, omdat zij weten wat het beste bij hen past. En daarnaast ook de top-downexpertise en prak- 
tische ondersteuning van externe partners, omdat zij de school kunnen helpen met hun kennis, ervaringen, en/of door de inzet van personeel [13].

Het proces van cocreatie lijkt extra te zijn gestimuleerd door het veroorzaken van een positieve disruptie [27], die gecreëerd is door de aangeboden lunch. Deze lunch heeft op de volledige GBT-scholen geleid tot meer discussie over en ruimte voor gezondheidsbevordering, waardoor het makkelijker werd voor deze scholen om meerdere gezondheidsbevorderende aanpassingen te doen. Dit geeft aanleiding voor andere scholen om bij het stimuleren van gezondheidsbevordering ook grotere gezondheidsbevorderende ontregelingen (disrupties) op school te overwegen, in plaats van kleine gezondheidsbevorderende aanpassingen. Deze kennis over het proces van cocreatie en positieve disruptie in relatie tot de schoolcontext is van meerwaarde voor het Nederlandse schoolgezondheidsbeleid [13]. In dit verband is het positief dat het landelijk programma Gezonde School ook de wijk en de schoolcontext meeneemt in de praktische uitwerking op schoolniveau. Wat betreft het disruptieve element en het intensieve cocreatieproces zijn er nog verbeterslagen te maken.

Tot slot, de GBT kan worden beschouwd als een haalbare en praktische vertaling van de principes van de HPS-benadering. Bij het evalueren van zo'n praktische aanpak is het van belang om niet alleen te onderzoeken óf deze werkt, maar ook hoe, waar, voor wie en onder welke omstandigheden, zodat de invloed van de schoolcontext op de effecten zichtbaar wordt.

\section{Conclusie}

Alles bij elkaar genomen kan geconcludeerd worden dat GBT, als haalbaar gebleken uitwerking van de HPS-benadering, een veelbelovend initiatief is dat de gezondheid en het gezondheidsgedrag van kinderen op passende en effectieve wijze kan verbeteren. De schoolcontext is hierbij op diverse manieren van invloed op de effecten. Wanneer scholen als complex en adaptief worden beschouwd, kan dat bijdragen aan een betere integratie en evaluatie van gezondheidsbevordering op scholen.

Dankbetuiging Speciale dank gaat uit naar alle scholen, kinderen en ouders die hebben meegewerkt, en naar de Provincie Limburg en andere samenwerkingspartners van de GBT.

Open Access This article is licensed under a Creative Commons Attribution 4.0 International License, which permits use, sharing, adaptation, distribution and reproduction in any medium or format, as long as you give appropriate credit to the original author(s) and the source, provide a link to the Creative Commons licence, and indicate if changes were made. The images or other third party material in this article are included in the article's Creative Commons licence, unless indicated otherwise in a credit line to the material. If material is not included in the article's Creative Commons licence and your intended use is not permitted by statutory regulation or exceeds the permitted use, you will need to obtain permis- sion directly from the copyright holder. To view a copy of this licence, visit http://creativecommons.org/licenses/by/4.0/.

\section{Literatuur}

1. Bonell C, Parry W, Wells H, Jamal F, Fletcher A, Harden A, et al. The effects of the school environment on student health: a systematic review of multi-level studies. Health Place. 2013;21:180-91.

2. WHO. Ottawa Charter for health promotion: an international conference on health promotion: the move towards a new public health, November 17-21. Ottawa: World Health Organization; 1986.

3. Deschesnes M, Martin C, Hill AJ. Comprehensive approaches to school health promotion: how to achieve broader implementation? Health Promot Int. 2003;18(4):387-96.

4. Turunen H, Sormunen M, Jourdan D, Seelen J von, Buijs G. Health Promoting Schools - a complex approach and a major means to health improvement. Health Promot Int. 2017;32(2):177-84.

5. Schools for Health in Europe. SHE Manual. Haderslev: Schools for Health in Europe. 2020. https://www. schoolsforhealth.org/resources/materials-and-tools/howbe-health-promoting-school. Geraadpleegd op 6 januari 2020.

6. Rijksoverheid. Gezonde school programma 2017-2020. Den Haag: Rijksoverheid; 2016.

7. Bartelink N, Bessems K. Health promoting schools in Europe: state of the art. Maastricht: SHE; 2019.

8. Jansen M, Kuppens E. Op zoek naar de Limburg-factor. Geleen: GGDZuid Limburg; 2015.

9. Keshavarz N, Nutbeam D, Rowling L, Khavarpour F. Schools as social complex adaptive systems: a new way to understand the challenges of introducing the health promoting schools concept. Soc SciMed. 2010;70(10):1467-74.

10. Rosas SR. Systems thinking and complexity: considerations for health promoting schools. Health Promot Int. 2015;32(2):301-11.

11. Damschroder LJ, Aron DC, Keith RE, Kirsh SR, Alexander JA, Lowery JC. Fostering implementation of health services research findings into practice: a consolidated framework for advancing implementation science. Implement Sci. 2009;4(1):1.

12. BartelinkN. Evaluating health promotion in complexadaptive school systems: the healthy primary school of the future. Maastricht: Maastricht University; 2019.

13. Bartelink N, Assema Pvan, Jansen M, Savelberg H, Moore G, Hawkings J, et al. Process evaluation of the healthy primary school of the future: the key learning points. BMC Public Health. 2019;19(1):698.

14. Bartelink N, Assema P van, Jansen M, Savelberg H, Willeboordse M, Kremers S. The healthy primary school of the future: a contextual action-oriented research approach. Int JEnviron Res Public Health. 2018;15(10):2243.

15. Bartelink NH, Assema P van, Kremers SP, Savelberg HH, Oosterhoff M, Willeboordse M, et al. One-and two-year effects of the Healthy Primary School of the Future on children's dietary and physical activity behaviours: a quasiexperimental study. Nutrients. 2019;11(3):689.

16. Bartelink NH, Assema P van, Kremers SP, Savelberg HH, Oosterhoff M, Willeboordse M, et al. Can the Healthy Primary School of the Future offer perspective in the ongoing obesity epidemic in young children? A Dutch quasiexperimental study. BMJ Open. 2019;9(10):e030676.

17. Bartelink N, Assema P van, Jansen M, Savelberg H, Kremers S. The moderating role of the school context on the 
effects of the Healthy Primary School of the Future. Int J Environ Res Public Health. 2019;16(13):2432.

18. BartelinkN,AssemaPvan, KremersS, SavelbergH, GeversD, Jansen M. Unravelling the effects of the Healthy Primary School of the Future: for whom and where is it effective? Nutrients. 2019;11(9):2119.

19. Willeboordse M, Jansen M, Heijkant S van den, Simons A, Winkens B, Groot R de, et al. The Healthy Primary School of the Future: study protocol of a quasi-experimental study. BMCPublic Health. 2016;16(1):1.

20. Schönbeck Y, Talma H, Dommelen P van, Bakker B, Buitendijk SE, HiraSing RA, et al. Increase in prevalence of overweight in Dutch children and adolescents: a comparison of nationwide growth studies in 1980, 1997 and 2009. Plos One. 2011;6(11):e27608.

21. Evenson KR, Catellier DJ, Gill K, Ondrak KS, McMurray RG. Calibration of two objective measures of physical activity for children. J Sports Sci. 2008;26(14):1557-65.

22. Darlington EJ, Violon N, Jourdan D. Implementation of health promotion programmes in schools: an approach to understand the influence of contextual factors on the process? BMCPublic Health. 2018;18(1):163.

23. Poland B, Krupa G, McCall D. Settings for health promotion: an analytic framework to guide intervention design and implementation. Health Promot Pract. 2009;10(4):505-16.

24. WHO. Health promoting schools: a framework for action. Manila: World Health Organization Western Pacific Region; 2009.

25. Fleuren MA, Paulussen TG, Dommelen Pvan, Buuren Svan. Towards a measurement instrument for determinants of innovations. Int JQual Health Care. 2014;26(5):501-10.

26. Boudewijns E, Pepels J, Kann D van, Konings K, Schayck C van, Willeboordse M. Non-response and external validity in a school-based quasi-experimental study 'The Healthy PrimarySchool of theFuture': a cross-sectional assessment. Prev Med Rep. 2019. https://doi.org/10.1016/j.pmedr. 2019.100874.

27. Moore GF, Evans RE, Hawkins J, LittlecottH, Melendez-Torres G, Bonell C, et al. From complex social interventions to interventions in complex social systems: future directions and unresolved questions for intervention development and evaluation. Evaluation. 2019;25(1):23-45.

28. Peters LW, Dam GT ten, Kocken PL, Buijs GJ, Dusseldorp E, Paulussen TG. Effects of transfer-oriented curriculum on multiple behaviors in the Netherlands. Health Promot Int. 2013;30(2):291-309.

29. Lipsey MW. Design sensitivity: statistical power for experimental research. Pugey: SAGE; 1990.

30. Cook-Cottone C, CaseyCM, FeeleyTH, Baran J.Ameta-analytic review of obesity prevention in the schools: 1997-2008. Psychol Sch. 2009;46(8):695-719.

31. Lister-Sharp D, Chapman S, Stewart-Brown S, Sowden A. Health promotingschools and health promotion in schools: two systematic reviews. In Database of Abstracts of Reviews of Effects (DARE): quality-assessed reviews. London: Centre for Reviews and Dissemination; 1999.

32. Oosterhoff M, Joore M, Ferreira I. The effects of schoolbased lifestyle interventions on body mass index and blood pressure: a multivariate multilevel meta-analysis of randomized controlled trials. Obes Rev. 2016;17(11):1131-53.

33. Patton MQ. Developmental evaluation: applying complexity concepts to enhance innovation and use. New York: Guilford;2011.

34. Gubbels JS, Kann DH van, Vries NK de, Thijs C, Kremers SP. The next step in health behavior research: the need for ecological moderation analyses - an application to diet and physical activity at childcare. Int J Behav Nutr Phys Act. 2014;11(1):52.

35. Verjans-Janssen SR, KolkI van de, Kann DH van, Kremers SP, Gerards SM. Effectiveness of school-based physical activity and nutrition interventions with direct parental involvement on children's BMI and energy balance-related behaviors-a systematic review. PLoS ONE. 2018;13(9):e204560.

36. Kremers SP, Crutzen R. Nieuw leven in het fidelity-adaptation-debat. Tijdschr Gezondheidswet. 2018;96(1):11-3. 